\title{
Familial Low Birthweight Dwarfism with an Unusual Facies and a Skin Eruption
}

\author{
VICTOR DUBOWITZ
}

\author{
From the Department of Child Health, University of Sheffield
}

Though a number of dwarfs are readily recognized as belonging to a particular eponymous group, cases are still encountered that do not quite fit into any category.

The following patient is described in detail because of the unusual facies, the associated 'eczema', the apparent familial incidence and the resemblance to a number of cases reported in the American literature. It probably forms a distinct syndrome which should be recognizable on clinical grounds.

\section{Case History}

Amanda $R$. was born at term weighing only $5 \mathrm{lb}$. $6 \mathrm{oz}$. (2437 g.). From the outset she was a poor feeder and her weight gain was very slow. When she was referred to the Children's Hospital, Sheffield, at the age of 9 months, because of failure to thrive, her weight had cnly reached 9 lb. 9 oz. (4337 g.).

A skin eruption, mainly on the cheeks and round the eyes, first appeared at the age of I month. It disappeared within a few days of the application of a bland skin cream, but recurred later. At about 7 months an eruption varying in severity developed behind the knees and persisted. There was also a slight eruption in the elbow flexures and on the extensor surface of the forearms. There had not been any obvious correlation between the severity of the rash and exposure to sunlight, but there was no rash on unexposed parts of the body.

The mother could not recall the earlier milestones, but the girl sat unsupported in her pram at 7 months and on the floor at 9 months. She reached out for and grasped objects at 7 months, and at 8 months was able to chew, wave bye-bye, and play pat-a-cake.

On examination the most striking feature, apart from her small size, was the unusual facies (Fig. I and 2), with large and low set ears, a receding lower jaw, and the bridge of the nose in line with the forehead. An eruption resembling infantile eczema was present over the butterfly area of the face, at the angles of the mouth, around the ears, and in the flexures of the knees and elbows.

Received January 16, 1964.
The head circumference at $14 \frac{7}{8}$ in. $(37.8 \mathrm{~cm}$.) was commensurate with the body weight, both being atco the 5oth percentile for a 5-week-old infant. She was ? alert and took an active interest in her surroundings. She reached for objects with a mature two-finger grasp $\vec{N}$ (Fig. 3), and was able to sit unsupported for shorto periods. She had a very soft high-pitched cry and voice.

Radiographs of the wrist showed only one small $\bar{z}$ epiphysis corresponding to a bone age of about 20 months. Radiograph of the skull was normal. An intravenous pyelogram showed normal renal excretion and structure.

The blood count was normal; the serum Na 135 or $\mathrm{mEq}, \mathrm{K} 4 \cdot \mathrm{I} \mathrm{mEq}, \mathrm{Cr}$ ror $\mathrm{mEq}$, alkali reserve $22 \mathrm{mEq}$, urea $30 \mathrm{mg}$./100 ml..; $\mathrm{Ca} 10.8 \mathrm{mg} . / 100 \mathrm{ml}$., and sugar $98 \mathrm{mg}$./ $100 \mathrm{ml}$. Routine urine examination was normal. There was no abnormal aminoaciduria on chromato- $\bar{D}$ graphy. Urinary steroids per 24 hours were 17 keto- 0 steroids $0.4 \mathrm{mg}$., 17-ketogenic steroids $0.5 \mathrm{mg}$., $17-\frac{\AA}{\Omega}$ hydroxycorticoids $0.7 \mathrm{mg}$. A three-day fat balance: $\vec{F}$ dried faeces 7 g., total fat $34.5 \%$, daily output of fat $\stackrel{3}{3}$ $0.8 \mathrm{~g}$.

Course and Progress. Her motor and mental development advanced steadily. At Io months she started to crawl, was able to sit up from the supine, 0 and to pull herself into a standing position. When assessed at 13 months she was saying two words with. meaning, and was able to feed herself from a cup witho a spout or from her bottle. She stood with support $₹$ and walked with both hands held (Fig. 4). She waso able to match two cubes and to place one on the top of the other. Her weight was 12 lb. (5443 g.) (50th percentile for 3 months) and length 25 in. $(63.5 \mathrm{~cm}$.) (50th percentile for 6 months). The crown to pubis $N$ length was 15 in. $(38.1 \mathrm{~cm}$.) and the arm span 23 in. $(58.4 \mathrm{~cm}$.). The circumference of the head was 16.5 in. 0 $(4 \mathrm{I} \cdot 8 \mathrm{~cm}$.), of the chest $16 \mathrm{in} .(40.6 \mathrm{~cm}$.), and of the abdomen 15 in. $(38 \cdot 1 \mathrm{~cm}$.).

The eruption on the face varied in severity and was most marked around the ears. During a brief spell of sunshine, when she was I year old, she had developed $\mathbb{D}$ marked erythema over the legs, arms, and neck. $\mathrm{At}^{+}$ I3 months there was still marked 'eczema' of the knee $\frac{T}{0}$ flexures, the outer aspect of the lower legs and the $\frac{\mathrm{O}}{\mathrm{D}}$ elbow flexures (Fig. 5 and 6). The face was also slightly affected. 

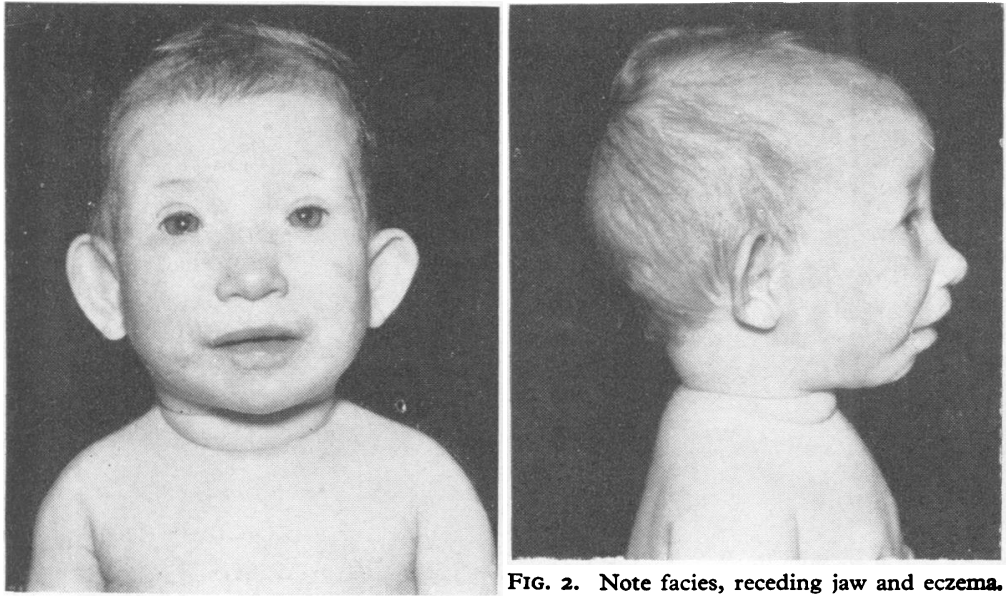

FIG. 2. Note facies, receding jaw and eczema.

Fig. I. Note unusual facies with large low-se ears. Eczema at angles of mouth and on cheeks.

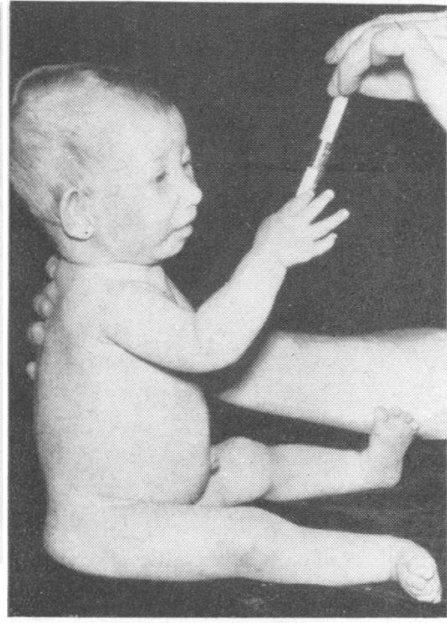

FIG. 3. Aged 9 months. Shows sitting posture and mature grasp.
Four teeth had erupted, two lower medial incisors and two upper teeth corresponding in position to the lateral incisors.

Radiograph of the upper dentition showed four deciduous incisors but only two permanent incisors (Fig. 7).

There was still only one small epiphysis on a repeat radiograph of the wrist, with little change from that at 9 months (Fig. 8).
The blood count was again normal. The serum Ca was $12 \mathrm{mg}$./ $100 \mathrm{ml}$., phosphorus $6 \mathrm{mg}$., and alkaline phosphatase 19 units (Jenner and Kay). On repeat analysis the $\mathrm{Ca}$ was $10.8 \mathrm{mg}$., phosphorus $4.9 \mathrm{mg}$., and alkaline phosphatase 16.0 units. The sodium was I $38 \mathrm{mEq}$, potassium $4.6 \mathrm{mEq}$, chloride $104 \mathrm{mEq}$, alkali reserve $23 \mathrm{mEq}$, and urea $24 \mathrm{mg}$./ $100 \mathrm{ml}$; transaminases: SGOT I06 units, SGPT 68 units; serum albumin $4.4 \mathrm{~g}$. $/ 100 \mathrm{ml}$., globulin $2.4 \mathrm{~g}$. $/ 100 \mathrm{ml}$; ; total

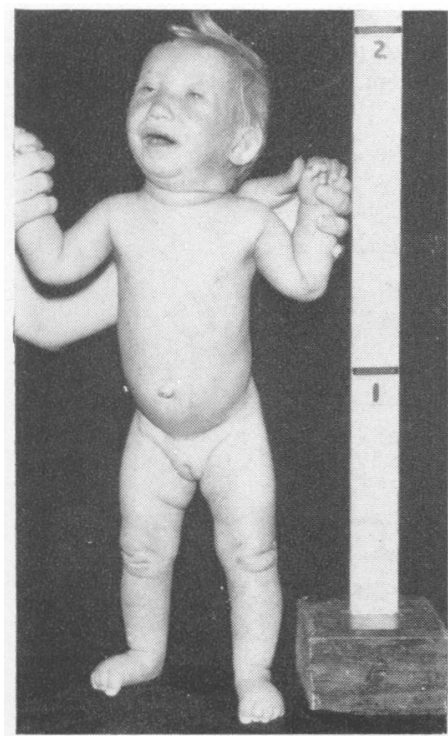

Fig. 4. Aged 13 months. Ability to stand with support.

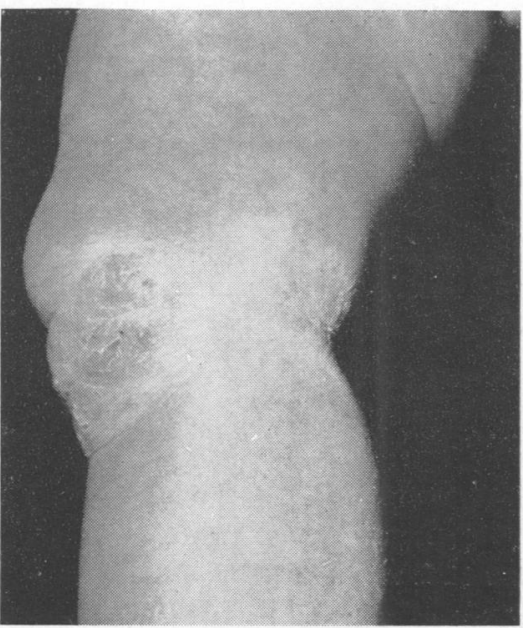

FIG. 5. Eczema of knee.

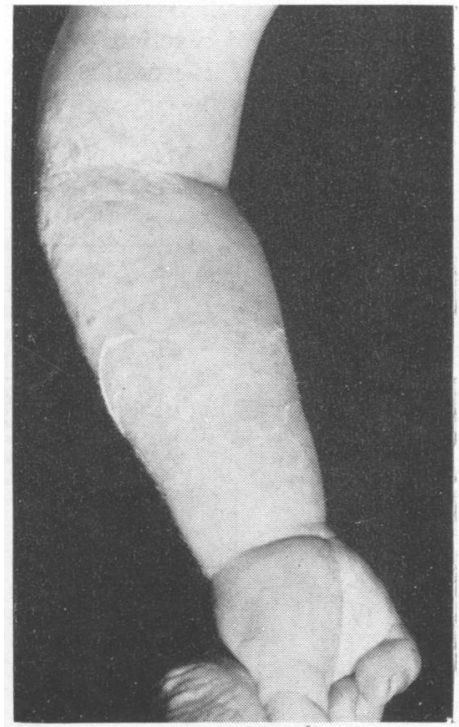

Fig. 6. Eczema of elbow and forearm. 


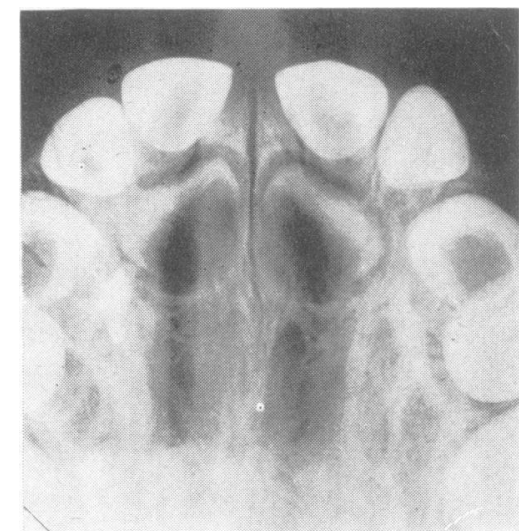

Fig. 7. Radiograph showing absence of upper lateral incisors in permanent dentition.

serum lipids $400 \mathrm{mg}$./100 ml., serum cholesterol 77 mg./100 ml.; vitamin A 86 units/100 ml. $(26 \mu \mathrm{g} . /$ I00 $\mathrm{ml}$.). The sweat sodium was $40 \mathrm{mEq} / \mathrm{litre}$. When repeated the total lipids were $610 \mathrm{mg} . / 100 \mathrm{ml}$; and the total cholesterol was $150 \mathrm{mg}$./100 ml. Electrophoresis showed a normal lipid distribution with $\alpha$ and $\beta$ fractions present.

Skin and leucocytes were cultured for chromosome analysis and showed a normal female karyotype.

The skin over the lumbar region was tested for sensitivity to ultraviolet light. The $\mathrm{E}_{1}$ dose of the lamp was 2 minutes. Testing doses of $1 \frac{1}{2}, 1 \frac{3}{4}, 2$, and $2 \frac{3}{4}$ minutes were given with resultant $E_{1}$ response for the first two exposures and $E_{2}$ response for the second two. The latter two exposure sites became pigmented and were still readily visible five months later, indicating the increased reaction to the ultraviolet radiation.

By the age of 16 months her weight had risen to

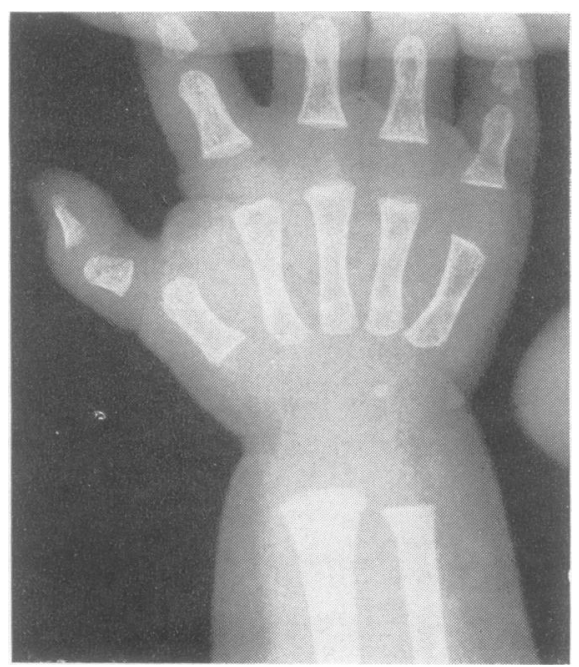

Fig. 8. Radiograph showing retardation of bone age. Taken at 13 months.

13 lb. 3 oz. (6.7 kg.). The eczema had shown some im- $\vec{\varphi}$ provement with I $\%$ hydrocortisone cream, but there was still a marked eruption, with some lichenification, in the elbow and knee flexures. No further teeth hado erupted. She was walking up to six steps without sup-ड port, was putting an arm out when dressed, and she helped with undressing. She was able to put a spoon-o ful of food into her mouth. She had not learnt any new words and was still only able to put the circle into the $\overrightarrow{\vec{A}}$

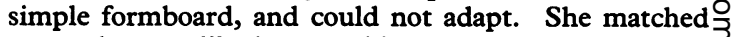
two cubes readily but would not make a tower with them. Her manipulative ability was assessed at about the ro-month level, and she was considered to be slightly retarded for her age.

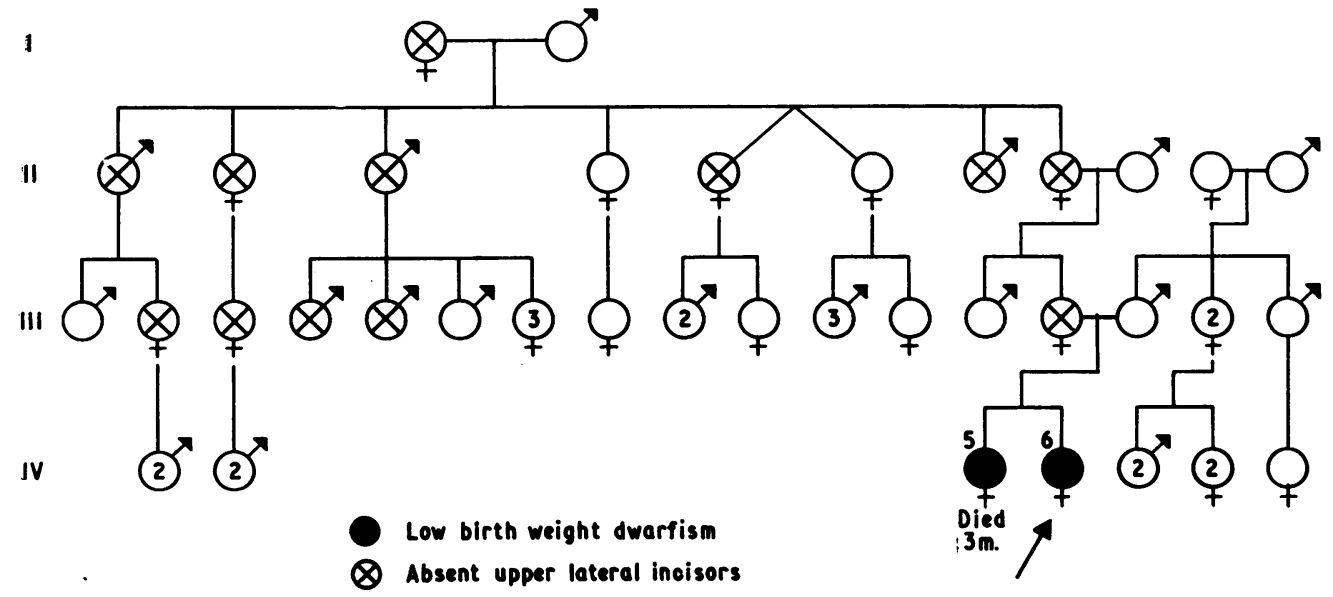

FIG. 9. Pedigree chart. 


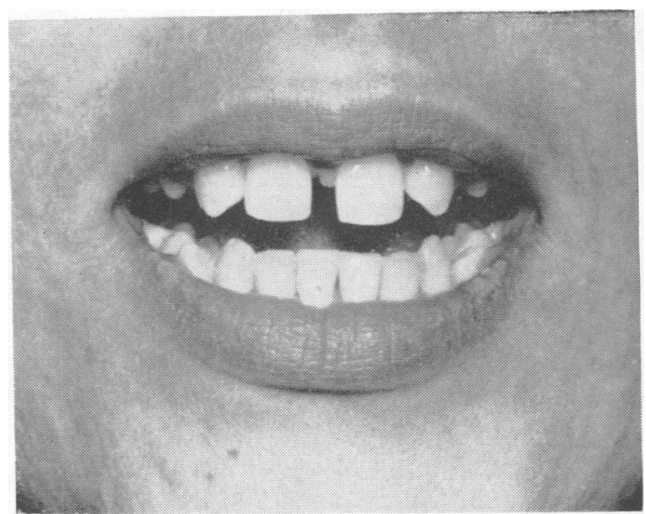

FIG. IO. Absence of upper lateral incisor teeth in mother.

When last examined at 18 months her weight had risen to $14 \mathrm{lb}$. $(6.35 \mathrm{~kg}$.) and her length was $27.5 \mathrm{in}$. $(69.8 \mathrm{~cm}$.). Four upper and two lower incisor teeth were present.

The eruption on the face and limbs had completely cleared within two weeks of her previous attendance, while she was still having hydrocortisone cream and had not recurred after this was stopped. During this period she had not been out of doors as frequently as before.

Her walking had improved considerably but she had not learnt any new words. She placed the circle in the simple formboard and could also adapt. She placed one cube on ancther but would not release it. She was still considered to be slightly retarded.

Family History. A female sib, with a similar facial appearance (IV. 5, Fig. 9) had a birth weight of only $4 \mathrm{lb}$. (I8I4 g.) at full term, and she remained in hospital until her death at 3 months. Her highest weight had been $4 \mathrm{lb}$. $8 \mathrm{oz}$. (204I g.). In addition she had webbing of the toes. There was no rash.

Both parents are of normal stature. The father is 70 in. ( $178 \mathrm{~cm}$.) tall and weighs $168 \mathrm{lb}$. (76 kg.), and the mother is 65 in. ( $165 \mathrm{~cm}$.) tall and weighs $140 \mathrm{lb}$. $(63.5 \mathrm{~kg}$.). It was noticed that the mother had only two upper incisor teeth (Fig. IO) and further questioning revealed a similar anomaly in the maternal grandmother and great-grandmother and a number of other members of the family (Fig. 9).

While pregnant with Amanda the mother developed blisters on both arms following exposure to the sun on three successive days. She had never previously had a severe reaction to sunlight, and usually tanned readily.

\section{Discussion}

The main clinical features in this patient are the low birthweight dwarfism, the peculiar facies, and the skin eruption on the face and extremities. The fact that a previous sib probably had a similar condition, while the parents are normal, suggests an autosomal recessive mode of inheritance.

The Table summarizes a number of similar cases that have been reported recently, and the following analysis is based upon it.

Skin. The condition first attracted the attention of dermatologists: in fact the first five cases listed were all shown at dermatological meetings. Torre (1954) thought that the erythematous lesions on the face resembled lupus erythematosus, but Bloom (1954a, b) suggested a congenital telan-

\section{TABLE}

\section{SUMMARY OF SIMILAR REPORTED CASES}

\begin{tabular}{|c|c|c|c|c|c|c|c|c|c|c|c|c|c|c|}
\hline $\begin{array}{l}\text { Case } \\
\text { No. }\end{array}$ & Reference & $\begin{array}{c}\text { Age } \\
\text { (yr.) }\end{array}$ & Sex & Familial & $\begin{array}{c}\text { Birth } \\
\text { Weight } \\
<2.5 \mathrm{~kg}\end{array}$ & $\begin{array}{c}\text { Weight } \\
< \\
\text { Height }\end{array}$ & $\begin{array}{c}\text { Bone } \\
\text { Age }\end{array}$ & I. $\mathbf{Q}$. & $\begin{array}{c}\text { Absent } \\
\text { Incisors }\end{array}$ & Face Limbs & $\begin{array}{l}\text { Light } \\
\text { Sensi- } \\
\text { tivity }\end{array}$ & $\begin{array}{c}\text { Café } \\
\text { au lait } \\
\text { patches }\end{array}$ & $\begin{array}{c}\text { Other } \\
\text { Con- } \\
\text { genital } \\
\text { Ab- } \\
\text { normali- } \\
\text { ties }\end{array}$ & Facies \\
\hline
\end{tabular}

\begin{aligned} \hline I & $\begin{array}{l}\text { Machacek (1953) } \\ \text { (quoted Bloom) }\end{array} \\ 2 &$ Torre (1954) \\ 3 & Bloom (1954) \\ 4 & Brunsting (1957) \\ 5 & Lewis (1957) \\ 6 & Hillman (1957) \\ 7 & Korting and Adam* (1958) \\ 8 & Katzenellenbogen (1960) \\ 9 & Katzenellenbogen (1960) \\ I0 & Szalay (1963) \\ I1 & Szalay (1963) \\ 12 & Szalay (1963) \\ 13 & Dubowitz (1964) \\ I4 & Dubowitz (1964) \end{aligned}

$\begin{array}{cllll}3 \frac{1}{2} & \mathbf{M} & - & & \\ 2 \frac{1}{2} & \mathbf{F} & - & + & \\ 20 & \mathbf{M} & - & + & \\ \mathbf{2 2} & \mathbf{M} & - & & \\ \mathbf{2 0} & \mathbf{M} & - & & \\ \mathbf{6} & \mathbf{M} & - & + & + \\ \mathbf{3 7} & \mathbf{M} & - & & + \\ \mathbf{2} \frac{1}{2} & \mathbf{M} & - & + & + \\ \mathbf{1 0} & \mathbf{M} & - & + & + \\ \mathbf{1 0} & \mathbf{M} & ? & + & + \\ \mathbf{1} & \mathbf{M} & + & + & + \\ \mathbf{8} & \mathbf{F} & + & + & + \\ \mathbf{1} \frac{1}{2} & \mathbf{F} & + & + & + \\ \text { d. } \frac{3}{12} & \mathbf{F} & + & + & \end{array}$

$\begin{array}{lll} & & \\ \mathbf{N} & \mathbf{N} & \\ \mathbf{N} & & \\ \mathbf{R} & & \\ \mathbf{N} & & \\ ? \mathbf{R} & \mathbf{N} & \\ \mathbf{N} & \mathbf{N} & \\ \mathbf{R} & \mathbf{R} & + \\ \mathbf{R} & \mathbf{N} & + \\ \mathbf{R} & \mathbf{R} & +\end{array}$

+
+
+
+
+
+
+
+

$\mathrm{d}=$ died; $\mathrm{N}=$ normal $\quad \mathrm{R}=$ retarded.

* A questionable case. 
giectatic erythema, which was more in keeping with the histological changes. In subsequent reports the clinical and histological descriptions of the skin lesions have varied considerably, but the distribution over the face and extremities has been fairly consistent. Sensitivity to sunlight was noted in practically all of them.

Facies. The striking facies may be more distinctive in this syndrome than the character of the skin eruption. Bloom (1954b) drew attention to the narrow fine-featured face of his patient, which gave the impression of precocious senility. There is a striking facial resemblance between Bloom's patient, that of Hillman, Crawford, and Talbot (1957), all three patients of Szalay (1963), the one patient illustrated by Katzenellenbogen and Laron (1960), and the present one. Brunsting (1957) and Lewis (1957) also claimed that their patients resembled Bloom's, but no photographs are included in their reports. While Korting and Adam (1958) considered their adult dwarf to have the same syndrome as that described by Bloom, the facial appearance in their illustration bears no resemblance. Case reports in the earlier literature of skin eruptions of the face and extremities in dwarfs, such as the three cases of Thomson (1923, 1936), can also be differentiated from the present syndrome on the basis of the different facial appearance. On the other hand one of the two personal cases included by Seckel (1960) in his monograph on bird-headed dwarfs probably belongs to this syndrome. This child weighed only $4 \mathrm{lb}$. 5 oz. (I956 g.) at birth and from the illustration does not appear to have a bird-like facies but bears a strong resemblance to the present case. There is, however, no mention of a skin eruption in Seckel's patient.

Weight. Hillman et al. (1957) pointed out that the weight of their patient was disproportionately low for the height. These corresponded to the $\mathrm{I} \frac{1}{2}$-year and 3-year level respectively in a 6-yearold patient. They suggested a hypocaloric form of dwarfism to explain this, but were unable to induce their patient to take a high calorie diet in order to prove it. The same discrepancy between height and weight was subsequently observed by Katzenellenbogen and Laron (1960) and Szalay (1963) in all their patients, and also in the present patient. The bone age has been retarded in four of the reported cases as well as in the present patient, but was normal in three others (excluding the case of Korting and Adam).
Intelligence. The intelligence has been re- $\stackrel{\mathbb{D}}{\vec{D}}$ garded as normal in the majority of reports. No detailed studies are given and it is possible that $a \overrightarrow{=}$ minimal degree of impairment, such as that of the present patient, may have been overlooked in some instances.

Biochemical Studies. Routine biochemical $\stackrel{\widetilde{\Omega}}{\Omega}$ studies of the blood and urine were found to bes normal by a number of authors and extensive $\overrightarrow{0}$ investigations of thyroid and adrenal function by $\overrightarrow{-}$ Bloom and by Katzenellenbogen and Laron gave $\vec{\sigma}$ normal results. The latter authors also found no benefit from anabolic steroid or insulin therapy.

Associated Defects. Associated congenital $\stackrel{\overrightarrow{-}}{\sim}$ abnormalities have been recorded in a number of ${ }_{0}^{N}$ cases. Café au lait patches occurred in 5; other abnormalities include ichthyosis and pilonidal $\vec{z}$ cyst (Bloom, I954b), supernumerary fingers (Torre, 1954), hypospadias and undescended testes (Katzen- $\widehat{O}$ ellenbogen and Laron, 1960), absence of upper $\vec{P}$ lateral incisors (Szalay, 1963), and webbed toes $\mathscr{S}$ (sib of present case). The absence of upper lateral ${ }^{\mathrm{T}}$ incisors in all three of Szalay's cases as well as in the permanent dentition of the present case is of special interest. This is a fairly common con-ō genital anomaly. Röse (1906), in a survey of I5,000 persons, found degeneration or absence of ${ }_{Q}^{D}$ the upper lateral incisors in $6 \%$ of Scandinavians, $\vec{\Rightarrow}$ $2-4 \%$ of Central Europeans, $1 \cdot 4 \%$ of Greeks, and 3 about $\mathrm{I} \%$ of coloured races. It was more common? in females than in males. Hrdlička (I92I) foundô. the incidence in American males to be $1 \cdot 4 \%$ and in females $3 \%$ A number of authors have re-⿳⺈ ported a familial incidence; inheritance is usuallyo dominant (Gates, 1946). This abnormality usually?. occurs as an isolated phenomenon, though it mayo be associated with other abnormalities such as hare-lip and cleft palate (Lucas, 1904). The ab-O sence of upper lateral incisors in various members $\supset$ of the family on the mother's side of the present? case follows an autosomal dominant inheritance. However, none of them is dwarfed or has any other: stigmata of the syndrome. In this family the anomaly of the teeth and the dwarfism may be coincidental, but the fact that Szalay's three patientș also had absence of the upper lateral incisorso suggests that there may be a linkage between the्ष two conditions.

Genetics. Bloom's (1954b) patient was the only $\frac{0}{\overrightarrow{0}}$ living child of healthy unrelated parents. A sib@ died at the age of 3 months of unknown cause. $\stackrel{\mathbb{Q}}{Q}$ 
The family history was negative. No mention of the family history was made in the patients of Torre (1954), Brunsting (1957), and Lewis (1957), and it is recorded as being non-contributory in the patient of Hillman et al. (1957). The first patient of Katzenellenbogen and Laron (I960) had healthy unrelated parents of normal stature and a healthy sib. In the second case the parents were of average height and unrelated, but the maternal grandfather was of short stature; three sibs were normal.

The possibility that the affection might be genetically determined was first suggested by Szalay (1963). The parents of his first patient were first cousins: there was no family history of similarly affected children and three sibs were normal. His second and third patients were a brother and sister, who had three normal sibs: their parents were normal and unrelated and their family history was negative.

Szalay's patients and the family recorded here suggest that the syndrome is inherited in a recessive manner. The chromosome pattern was found normal in Szalay's first patient and in the present study.

\section{Summary}

A female infant is described with low birthweight dwarfism, a peculiar facies, a skin eruption of the face and flexures, retarded bone age, slightly impaired intellectual development, and absence of the permanent upper lateral incisors. A previous sib, who probably also had the syndrome, died at the age of 3 months. Absence of the upper lateral incisors as an isolated anomaly occurs on the mother's side of the family as an autosomal dominant trait. Biochemical and chromosomal studies were normal. Similar reported cases are reviewed.
I wish to thank Professor R. S. Illingworth for his help and advice; Miss E. Finch for the biochemical investigations; Dr D. Noel Raine of Birmingham for the lipid studies; Dr P. M. Lord of the Genetics Department for the chromosome analysis; Miss M. C. Martin for the photosensitivity tests; Mr A. T. Tunstill for the illustrations; and Mr A. S. Forster for the pedigree chart.

REFERENCES

Bloom, D. (1954a). Congenital telangiectatic erythema in a LeviLorain dwarf. Arch. Derm., 69, 526.

(1954b). Congenital telangiectatic erythema resembling lupus erythematosus in dwarfs; probably a syndrome entity. Amer. F. Dis. Child., 88, 754.

Brunsting, L. A. (I957). Congenital telangiectasia of the face; ichthyosiform erythroderma?; mild pituitary dwarfism (LeviLoraine type). Arch. Derm., 75, 771.

Gates, R. R. (1946). Human Genetics, vol. I, p. 359. Macmillan, New York.

Hillman, D. A., Crawford, J. D., and Talbot, N. B. (1957). Observations on the etiology of dwarfism in congenital telangiectatic erythema. Pediatrics, 20, 268.

Hrdlička, A. (I92I). Further studies of tooth morphology. Amer. F. phys. Anthrop., 4, 141 .

Katzenellenbogen, I., and Laron, Z. (I960). A contribution to Bloom's syndrome. Congenital telangiectatic erythema resembling lupus erythematosus in dwarfs. Arch. Derm., 82, 609.

Korting, G. W., and Adam, W. (1958). Eine seltene PoikilodermieForm: Lupus erythematodes-artige Hautveränderungen bei Minderwuchs. Arch. Klin. exp. Derm., $207,508$.

Lewis, B. L. (1957). Discussion of Brunsting's case presentation. Arch. Derm., 75, 772.

Lucas, R. C. (1904). On an ill-developed upper lateral incisor tooth as a forerunner of harelip, and cleft palate. Brit. $\mathcal{F}$. Child. Dis., r, 483 .

Röse, C. (1906). Ueber die Rückbildung der seitlichen Schneidezähne des Oberkiefers und der Weisheits-zähne im menschlichen Gebisse. Dtsch. Mschr. Zahnheilk, 24, 225.

Seckel, H. P. G. (1960). Bird-headed Dwarfs. Studies in Developmental Anthropology Including Human Proportions. Thomas, Springfield, Illinois.

Szalay, G. C. (1963). Dwarfism with skin manifestations. $\mathcal{f}$. Pediat., 62, 686.

Thomson, M. S. (1923). A hitherto undescribed familial disease. Brit. F. Derm., 35, 455 .

- (1936). Poikiloderma congenitale. ibid., 48, 221.

Torre, D. P. (I954). Primordial dwarfism: discoid lupus erythematosus. Arch. Derm., 69, 51 I. 